Canadian Science Publishing

Applied Physiology, Nutrition, and Metabolism Physiologie appliquée, nutrition et métabolisme

\title{
The effects of combined probiotic ingestion and circuit training on muscular strength and power and cytokine responses in young males
}

\begin{tabular}{|r|l|}
\hline Journal: & Applied Physiology, Nutrition, and Metabolism \\
\hline Manuscript ID & apnm-2017-0464.R1 \\
\hline Manuscript Type: & Article \\
\hline Complete List of Authors: & $\begin{array}{l}\text { Ibrahim, Nur Syazwani; University Sains Malaysia - Health Campus, } \\
\text { Exercise and Sports Science Programme } \\
\text { Muhamad, Ayu ; University Sains Malaysia - Health Campus, Exercise and } \\
\text { Sports Science Programme } \\
\text { Ooi, Foong; University Sains Malaysia - Health Campus, Exercise and } \\
\text { Sports Science Programme } \\
\text { Meor-Osman , Jamaayah; University Sains Malaysia - Health Campus, } \\
\text { Exercise and Sports Science Programme } \\
\text { Chen, Chee; University Sains Malaysia - Health Campus, Exercise and } \\
\text { Sports Science }\end{array}$ \\
\hline $\begin{array}{r}\text { Is the invited manuscript for } \\
\text { consideration in a Special } \\
\text { Issue? : }\end{array}$ & \\
\hline Keyword: & IL-6, IL-10, supplement, isokinetic, exercise \\
\hline
\end{tabular}




\section{Title page}

Title:

The effects of combined probiotic ingestion and circuit training on muscular strength and power and cytokine responses in young males

\section{Authors list:}

Nur Syazwani Ibrahim, Ayu Suzailiana Muhamad, Foong Kiew Ooi, Jamaayah Meor-Osman \& Chee Keong Chen

\section{Corresponding author:}

Associate Professor Dr. Chee Keong Chen

E-mail: ckchen@usm.my

Address: Exercise and Sports Science Programme, School of Health Sciences, Universiti Sains

Malaysia, 16150 Kota Bharu, Kelantan, Malaysia

Phone number: +6097677787

Fax number: + 6097677830

\section{Authors' name, email and affiliation:}

${ }^{1,2}$ Nur Syazwani Ibrahim, , ${ }^{1,3}$ Ayu Suzailiana Muhamad, ${ }^{1,4}$ Foong Kiew Ooi, ${ }^{1,5}$ Jamaayah Meor-Osman $\&{ }^{1,6}$ Chee Keong Chen

${ }^{1}$ Exercise and Sports Science Programme, School of Health Sciences, Universiti Sains Malaysia, 16150 Kota Bharu, Kelantan, Malaysia

2nsyazwani.mail@gmail.com, ${ }^{3}$ ayu_suzailiana@usm.my, ${ }^{4}$ fkooi@usm.my, ${ }^{5}$ jamaayah@usm.my, ${ }^{6}$ ckchen@usm.my 


\title{
Original Research
}

\begin{abstract}
To our knowledge, the efficacy of combined probiotic supplementation with circuit training has not been evaluated. Thus, we investigated the effects of probiotic supplementation combined with circuit training on isokinetic muscular strength and power and cytokine responses in young males. Fortyeight healthy sedentary young males were recruited and randomised into four separate groups: sedentary placebo control $(\mathrm{C})$, probiotics $(\mathrm{P})$, circuit training with placebo $(\mathrm{CT})$, and circuit training with probiotics (CTP). Participants in the CT and CTP groups performed circuit training 3 times/week with 2 circuits of exercises from weeks 1-8 followed by 3 circuits of exercises from weeks 9-12. Participants in the P and CTP groups consumed multi-strain probiotics containing $3 \times 10^{10} \mathrm{CFU}$ of $L$. acidophilus, L. lactis, L. casei, B. longum, B. bifidum and B. infantis twice daily for 12 weeks. Measurements of body height and weight, blood pressure, resting heart rate, blood samples and isokinetic muscular strength and power were carried out at pre and post-tests. Isokinetic knee strength and power in CT and CTP groups were significantly higher $(P<0.05)$ at post-test. In addition, interleukin (IL)-10 concentration was significantly increased $(P<0.0001)$ at post-test in P and CT but a trend toward significant increase in CTP $(P=0.09)$. Nevertheless, there was no significant difference in IL-6. This study suggests that 12 weeks of circuit training alone and the combination of circuit training and probiotic consumption improved muscular performance while circuit training alone and probiotics alone increased IL-10 concentration.
\end{abstract}

Keywords - supplement, exercise, isokinetic, IL-6, IL-10 


\section{Introduction}

The role of commensal microbiota in bolstering our health has been extensively carried out by many researchers (Daliri and Lee 2015; de Almada et al. 2015). Probiotics are defined by the World Health Organisation (WHO) as "live microorganisms that, when administered in adequate amounts, confer a health benefit on the host" (FAO 2002). These non-pathogenic microorganisms can be found in fermented food products such as yoghurt, kefir, tempeh, cabbage kimchee, sauerkraut, natto, soybeanbased miso, and probiotic drink.

The diversity of microbiota composition whether in a multi-strain probiotic or in a single strain probiotic has been proposed as a supplement as it can modulate the anti-inflammatory (i.e., IL10) and pro- (i.e., IL-6) cytokines in the body to promote a better health over the course of training (Jäger et al. 2016; Pedersen et al. 2001). The mechanisms of probiotics that actually help to regulate inflammation include (1) indirect effects by boosting the production of short chain fatty acids with anti-inflammatory properties (Vinolo et al. 2011), increasing the synthesis of antimicrobial peptides that influence inflammation resolution pathways in the mucosa (Schlee et al. 2008), as well as protecting or repairing epithelial barriers (Bermudez-Brito et al. 2012; Thomas and Versalovic 2010), and (2) direct effects by binding with the innate immune receptors (Thomas and Versalovic 2010) and triggering pathways that will cause the production of cytokines related with the inflammation (Jeon et al. 2012). Nevertheless, despite this attention to probiotics, studies done to investigate the effects of probiotics and exercise training are scarce, especially on muscular performance.

Circuit training which involves resistance exercise has been shown to improve muscular strength and power (Chen et al. 2014; Lau and Ooi 2014). However, besides muscular improvement, muscular damage may also occur especially among the sedentary population when they participate in resistance training (Chevion et al. 2003; Roth et al. 2000). The inflammation occurred in the muscle is one of the important mechanism for muscular adaptation towards exercise so that the muscle can regenerate and repair itself (Peake et al. 2017). Longer period to recover may interrupt daily activities and lead to a longer break from physical exercise. Nevertheless, the consumption of probiotics was 
believed to play a role with nutrients in the intestines (Sheridan et al. 2014) leading to beneficial effect in faster the muscle recovery rate (Jäger et al. 2015).

To date, evidence of the combined effects of resistance exercise and probiotic supplementation on interleukins and muscular performance is still lacking. Therefore, the present study was proposed to investigate the combined effects of probiotic supplementation with circuit training on muscular strength and power and cytokine responses in young males following 12 weeks of the intervention period.

\section{Methods}

\section{Participants}

In this study, 48 participants were recruited via snowball sampling among Universiti Sains Malaysia students after considering possibilities of drop-out. The inclusion criteria included (1) healthy young males with a sedentary lifestyle (not engaged in any physical training programme and exercise no more than twice per week), (2) age between 19 to 26 years old and (3) not consuming any nutritional supplements or ergogenic aids prior to the study. The exclusion criteria include (1) smoking/vaping, (2) on medication and (3) having chronic diseases.

\section{Research procedures}

A randomised, parallel, placebo-controlled study design was employed. The procedure for this study has been approved by the Human Research Ethics Committee, Universiti Sains Malaysia, Kelantan (JEPeM Code: USM/JEPeM/15040132) and was in accordance with the Declaration of Helsinki as revised in 1983. The participants signed an informed consent form prior to participating in the study. Measurements were conducted at pre and post-test of the 12 weeks intervention period. The measurements included body height (SECA, UK) and weight (TANITA TBF-410, Japan), blood pressure and resting heart rate (OMRON, Japan), $4 \mathrm{~mL}$ of blood samples, isokinetic muscular strength and power test (Biodex System 3 Pro, New York, USA). 
Then, the participants were randomly assigned into 4 groups based on their age and BMI (see Fig. 1): 12 weeks of sedentary with placebo supplementation group (C), sedentary with probiotic supplementation group (P), circuit training with placebo group (CT), and 12 weeks of circuit training combined with probiotic supplementation group (CTP). A checklist to record participant's weekly activity and adherence to the supplementation regimen was given to the participants.

Post-test measurements, which were similar to the pre-test measurements, were carried out following the 12 weeks intervention period. Subsequently, blood serum for IL-6 and IL-10 were analysed based on enzyme-linked immune sorbent assay (ELISA) method by using a reagent kit (Human IL-6 and IL-10 ELISA Kit, China).

\section{Probiotic and placebo supplementation}

The probiotic and placebo used in this study were prepared by B Crobes Laboratory Sdn. Bhd. which was registered with the Malaysian Ministry of Health (121/14) and was certified Halal (A15766). The participants consumed two sachets of probiotic per day (P and CTP) or placebo (C and CT) for 12 weeks. Probiotic $(\mathrm{MCP}=$ microbial cell preparation) used in this study was known as Hexbio $\mathbb{C}$ granule and it contains 6 different microorganism strains (L. acidophilus BCMC® 12130, L. casei $B C M C \circledR$ 12313, L. lactis BCMC® 12451, B. bifidum BCMC® 02290, B. infantis BCMC® 02129 and B. longum $\left.B C M C{ }^{\circledR} 02120\right)$ in each sachet with a concentration of $3 \times 10^{10}$ colony-forming unit (CFU) during the manufacturing. It is an orange flavoured and cream colour granular powder. The nutritional compositions in each of the probiotics sachet are carbohydrate (2.0g), lactose (1.28g), sugar $(0.12 \mathrm{~g})$, protein $(0.16 \mathrm{~g})$, fat $(0.01 \mathrm{~g})$, fibre $(0.01 \mathrm{~g})$ and with an energy value of $(11.55 \mathrm{kcal})$. As for placebo, it was identical in shape, taste and colour to the probiotics but contained no bacteria.

\section{Circuit training programme}

Participants in the CT and CTP groups performed circuit training 3 times per week with 2 circuits of exercises from weeks 1-8 followed by 3 circuits of exercises from weeks 9-12. Each circuit comprised 10 stations (one type of exercise per station) with work to rest ratio of $1: 2$ and the resting period between circuits were 5 minutes. The exercises included heel raise with dumbbell, side lateral raise 
with elastic band, leg abduction with elastic band, shoulder extension and flexion using elastic band, rope skipping, triceps extension with dumbbell, half squat with elastic band, standing chest fly with dumbbell, leg curl with elastic band as well as biceps curl with dumbbell. The weight of the dumbbell and elasticity of the elastic band used was progressively increased $1-2.5 \mathrm{~kg}$; depending on individuals' capacity after 5 weeks of intervention and remained the same until the end of the 12 weeks of intervention. The prescribed exercise regimen used in this study has been used in several previous studies (Chen et al. 2016; Lau and Ooi 2014; Ooi et al. 2015).

\section{Isokinetic muscular strength \& power measurement}

The muscular performance of the participants was measured during pre and post-tests by measuring their muscular strength (peak torque) and power via an isokinetic dynamometer (Biodex System 3 Pro, New York, USA). The two angular velocities used to measure flexion and extension of the knee were $90^{\circ} . \mathrm{s}^{-1}$ and $300^{\circ} . \mathrm{s}^{-1}$. These angular velocities were chosen based on other similar studies (Chen et al. 2016; Ooi et al. 2015).

To begin the test, the participant was seated while leaning against a backrest tilted $85^{\circ}$ from the horizontal plane. The participant's shoulder, waist and thigh were strapped to minimise body movement and to ensure stabilisation of the body during the test. The lateral femoral epicondyle was used as the body landmark for matching the axis of rotation of the dynamometer resistance adapter. Once the participant was seated in a position that allowed for a comfortable and unrestricted motion for the knee extension and flexion (from a position of $90^{\circ}$ of flexion to terminal extension), the following measurements were taken: seat height, seat inclination, dynamometer head height and resistance pad level. These measurements were recorded and stored on the Biodex Advance Software program in an attempt to identify and reproduce similar testing positions for each individual participant. Gravity correction was obtained by measuring the torque exerted on the dynamometer resistance adapter with the knee in the relaxed state at the terminal extension.

Before the testing began, the procedure was fully informed to the participants. They were asked to do 5 repetitions for the $90^{\circ} . \mathrm{s}^{-1}$ angular velocity and 10 repetitions for the $300^{\circ} . \mathrm{s}^{-1}$ angular 
velocity. The participant was given 60 seconds to rest between the two angular velocities. The testing was repeated on the other side of the limb. All testing procedures as well as verbal encouragement were given by the same investigator for all participants.

\section{Statistical analysis}

Statistical analysis was performed by using Statistical Package for Social Sciences (SPSS) version 22.0. Mixed-factorial analysis of variance (ANOVA) was performed to determine the significance of differences between and within groups. Differences considered significant at $P<0.05$. Results were reported as the means \pm standard deviations $(\mathrm{SD})$.

\section{Results}

\section{Physiological characteristics of the participants}

Forty-eight participants were recruited at the beginning of the study with twelve participants per group. However, seven participants dropped out during the intervention due to personal reasons and did not complete post-test measurements. The mean age, body height, body weight, body mass index (BMI),body fat percentage, mean resting heart rate and systolic and diastolic blood pressure of the participants according to the group are shown in Table $\mathbf{1 .}$

\section{Adherence to the training and supplementation regimen}

The total training days during the 12 weeks intervention was 36 days. The adherence rate of the participants to the exercise training was more than $90 \%$. A total of 168 sachets (either placebo or probiotics) should be consumed by each participant during the 3 months intervention period and the adherence to the supplementation regimen was more than $95 \%$.

\section{Probiotics/placebo combined with exercise training increases muscular strength and power}

Results for the muscular strength and power are presented in Fig. 2. There were no significant differences in all the measured parameters between all the groups. However, isokinetic knee strength and power in CT and CTP groups were significantly higher in dominant knee peak torque at $90^{\circ} . \mathrm{s}^{-1}(P$ $=0.005)$, dominant knee extension average power at $300^{\circ} \cdot \mathrm{s}^{-1}(P=0.002)$, dominant knee flexion 
average power at $300^{\circ} . \mathrm{s}^{-1}(P=0.042)$, non-dominant knee extension peak torque at $90^{\circ} . \mathrm{s}^{-1}(P=$ $0.034)$, non-dominant knee flexion peak torque at $90^{\circ} \cdot \mathrm{s}^{-1}(P=0.004)$, non-dominant knee extension average power at $300^{\circ} . \mathrm{s}^{-1}(P=0.038)$, and non-dominant knee flexion average power at $300^{\circ} . \mathrm{s}^{-1}(P=$ $0.002)$ at post-test when compared to respective pre-test values.

Probiotics alone and exercise alone increases serum IL-10 concentration

There were no significant differences in all the measured parameters between all the groups (Table 2). Nevertheless, further analysis showed that there was a significant difference $(P=0.001)$ in mean serum IL-10 concentration at post-test compared to pre-test in P and CT groups.

Probiotics/placebo or with/without exercise has no effects on serum IL-6 concentration

There were no significant differences in all the measured parameters between all the groups (see Table 2). Further analysis also showed that there was also no significant difference of mean serum IL6 concentration within each group based on time $(P=1.00)$.

\section{Discussion}

Our results indicated that there were no significant differences between the control (C), exercise alone $(\mathrm{CT})$, probiotics alone $(\mathrm{P})$, and the combined probiotics and exercise $(\mathrm{CTP})$ group on the muscular strength and power measured in the present study. However, significant increases were observed after the 12 weeks intervention period in the CT and CTP groups. It is well accepted that resistance exercise is known to induce muscular strength and power (Alcaraz et al. 2011; Arazi and Asadi 2012; Chtara et al. 2008). The increment in muscular strength and power during the first few weeks of resistance training has been attributed to the neural adaptations (Moritani and deVries, 1979). These adaptations provide more efficient neural pathways along the route to the muscles. The consequence is an increased activation of synergistic muscles, along with the inhibition of neural protective mechanisms (Folland and Williams 2007), and thus induces the muscle's ability to generate more force. In the present study, participants in both CT and CTP groups followed the exercise training programme for 12 weeks. Thus, the observed increase in muscular strength and power in these two groups could also be attributed to the hypertrophy of the muscle fibres (Sale 1988). 
The combined effect of probiotic and exercise which lead to improvement in muscular strength and power was also reported in the previous study (Georges et al. 2014; Jäger et al. 2016). Even though the mechanism of the probiotics and its relation to the muscular strength is unclear, the significant increment obtained in the present study may be attributed to the probiotics mechanism that may have the tendency to increase the protein absorption in the body.

In addition, our data also indicated that there was an increasing trend in muscular strength and power among the participants in the $\mathrm{P}$ group despite the absence of statistical significance in the present study. This shows that the probiotic consumption alone may potentially improve the muscular strength. Despite negligible findings in the literature to support this trend, the consumption of probiotics may be associated with the energy enhancement that helped produce more strength in the muscles. In the body, especially in the human gut, there is a process known as carbohydrate fermentation that was known to be the core activity of the human gut microbiota that causes the production of energy and carbon metabolism of the colon (Lamprecht and Frauwallner 2012). Moreover, the interaction of the microorganism in the gastrointestinal lining with the range of end products generated by protein digestion for instance amino acids was also believed to enhance energy production in the body (Kimmel et al. 2010; Lamprecht and Frauwallner 2012) and hence may have resulted in the increment trend in muscular strength observed in the current study.

Furthermore, the finding of a significant increase in IL-10 concentration in the CT group was similar to a study done by Calle and Fernandez (2010). Muscle contractions induced by exercise training employed in this study may have caused muscular damage (Calle and Fernandez 2010). Therefore, increased IL-10 production could be a concomitant inflammatory response. In addition, it was also speculated that the resistance exercise might affect the magnitude of metabolic demand or the fatigue which may further influence the increment in the cytokine response patterns (Izquierdo et al. 2009) that may explain the increasing concentration of IL-10 in the present study.

Similar significant increment was also observed in the $\mathrm{P}$ group after the 12 weeks intervention. This finding is consistent with the other studies that also found an increment in the IL-10 
concentration after consuming probiotics (Čitar et al. 2014; Sheil et al. 2006). Despite muscular damage and fatigue as observed in CT group, the increment of IL-10 concentration in the Proup could have played an important role in ameliorating the symptoms of inflammatory bowel diseases. Some of the participants in the $\mathrm{P}$ group did mention that they were having diarrhoea and this problem was eventually solved after taking the probiotic supplement. Hence, this provides a rationale use of probiotic supplement for the treatment of gastrointestinal inflammation as it already had been proven in other studies (Goldenberg et al. 2015; Guandalini 2011). For that reason, it is important to monitor the symptoms of inflammatory bowel diseases for future studies. The trend of IL-10 concentration in the CTP group also increased after 12 weeks of intervention. To our knowledge, there is no other study to support this result at the moment as research in this area is very scarce. Nevertheless, this might be due to the reduction in muscle damage that speeds up recovery rate. Probiotics have been reported to lessen the severity, number, and duration of infections in athletes (Cox et al. 2010; Gleeson et al. 2011; Haywood et al. 2014). Hence, the probiotic consumption was believed to interact with nutrients absorption (Sheridan et al. 2014) leading to beneficial faster muscle recovery rate (Jäger et al. 2015). The probiotics increase the gut lining cells health by enhancing the nutrient absorption including minerals, peptides and amino acids by lowering the inflammation rate and supporting optimum development of the absorptive area of the villi (Kimmel et al. 2010).

No significant difference was observed in IL-6 after the intervention period. Nevertheless, its increasing trend was observed at post-test measurement. The increasing trend in IL-6 concentration in the present study was consistent with a study done by Cullen et al. (2016). It has been reported that contracting muscles contribute to most of the IL-6 present in the circulation in response to exercise where, the magnitude of the exercise-induced IL-6 response is dependent on the intensity and especially duration of the exercise, while the mode of exercise has little effect. However, a prolonged exercise involving a significant muscle mass in the contractile activity is necessary in order to produce a marked systemic IL-6 response. Thus, our prescribed circuit training program may not have reached the required intensity and duration to elicit the significant increase in IL-6. Shing et al. (2014) also reported that probiotic supplementation caused increased in plasma concentrations of IL-6 and IL-10. 
Smaller perturbation was also observed in IL-6 and IL-10 concentrations after 11 weeks of probiotic supplementation in males and females competitive cyclists (West et al. 2011).

In summary, between group effects showed that interleukin responses and muscular performance were not significantly different between control, probiotics alone, exercise alone, and the combination of probiotics and exercise groups. However, exercise alone showed significantly increased in most of the immune cells count measured, such as IL-10 concentration; and muscular strength and power in both dominant and non-dominant legs. Probiotics alone significantly increased IL-10 concentration but not the other measured parameters. In addition, this combination also significant increases muscular power and strength in both legs of the participants but the other measured parameters were not significantly affected.

Hence, this study suggests that 12 weeks of circuit training alone and the combination of circuit training and probiotic consumption improved muscular performance while circuit training alone and probiotics alone increased IL-10 concentration.

\section{Acknowledgements}

The author would like to thank the participants for participating in this research, laboratory staff of Sports Science Laboratory for analysing the samples. This study was financially supported by a USM Research University grant (1001/PPSP/812184). We would also like to thank B Crobes Laboratory Sdn. Bhd. for sponsoring the probiotics and the placebo.

\section{Conflict of interest}

The authors have no conflict of interest. 


\section{References}

Alcaraz, P. E., Perez-Gomez, J., Chavarrias, M., \& Blazevich, A. J. 2011. Similarity in adaptations to high-resistance circuit vs. traditional strength training in resistance-trained men. J. Strength Cond. Res. 25(9), 2519-2527. doi: 10.1519/JSC.0b013e3182023a51.

Arazi, H., \& Asadi, A. 2012. Multiple sets resistance training: Effects of Condensed versus circuit models on muscular strength, endurance and body composition. J. Hum. Sport Exerc. 7(4), 8. doi: $10.4100 /$ jhse.2012.74.01.

Bermudez-Brito, M., Plaza-Díaz, J., Muñoz-Quezada, S., Gómez-Llorente, C., \& Gil, A. 2012. Probiotic Mechanisms of Action. Ann. Nutr. Metab. 61(2), 160-174.

Calle, M. C., \& Fernandez, M. L. 2010. Effects of resistance training on the inflammatory response. Nutr. Res. Pract. 4(4), 259-269. doi: 10.4162/nrp.2010.4.4.259.

Chen, C. K., Hamdan, N. F., Ooi, F. K., \& Wan Abd Hamid, W. Z. 2016. Combined Effects of Lignosus rhinocerotis Supplementation and Resistance Training on Isokinetic Muscular Strength and Power, Anaerobic and Aerobic Fitness Level, and Immune Parameters in Young Males. Int. J. Prev. Med. 7, 107. doi: 10.4103/2008-7802.190604.

Chen, C. K., Mohamad, W. M. Z. W., Ooi, F. K., Ismail, S. B., Abdullah, M. R., \& George, A. 2014. Supplementation of Eurycoma longifolia Jack Extract for 6 Weeks Does Not Affect Urinary Testosterone: Epitestosterone Ratio, Liver and Renal Functions in Male Recreational Athletes. Int. J. Prev. Med. 5(6), 728-733.

Chevion, S., Moran, D. S., Heled, Y., Shani, Y., Regev, G., Abbou, B., et al. 2003. Plasma antioxidant status and cell injury after severe physical exercise. Proceedings of the National Academy of Sciences, 100(9), 5119-5123. doi: 10.1073/pnas.0831097100.

Chtara, M., Chaouachi, A., Levin, G. T., Chaouachi, M., Chamari, K., Amri, M., et al. 2008. Effect of concurrent endurance and circuit resistance training sequence on muscular strength and power development. J. Strength Cond. Res. 22(4), 1037-1045. doi: 10.1519/JSC.0b013e31816a4419. 
Čitar, M., Hacin, B., Tompa, G., Štempelj, M., Rogelj, I., Dolinšek, J., et al. 2014. Human intestinal mucosa-associated Lactobacillus and Bifidobacterium strains with probiotic properties modulate IL-10, IL-6 and IL-12 gene expression in THP-1 cells. Beneficial Microbes, 6(3), 325-336. doi: 10.3920/BM2014.0081.

Cox, A. J., Pyne, D. B., Saunders, P. U., \& Fricker, P. A. 2010. Oral administration of the probiotic Lactobacillus fermentum VRI-003 and mucosal immunity in endurance athletes. Br. J. Sports Med. 44(4), 222-226. doi: 10.1136/bjsm.2007.044628.

Cullen, T., Thomas, A. W., Webb, R., \& Hughes, M. G. 2016. Interleukin-6 and associated cytokine responses to an acute bout of high-intensity interval exercise: the effect of exercise intensity and volume. Appl. Physiol. Nutr. Metab. 41(8), 803-808. doi: 10.1139/apnm-2015-0640.

Daliri, E. B.-M., \& Lee, B. H. 2015. New perspectives on probiotics in health and disease. Food Science and Human Wellness, 4(2), 56-65. doi: http://doi.org/10.1016/j.fshw.2015.06.002.

de Almada, C. N., Nunes de Almada, C., Martinez, R. C. R., \& Sant'Ana, A. d. S. 2015. Characterization of the intestinal microbiota and its interaction with probiotics and health impacts. Appl. Microbiol. Biotechnol. 99(10), 4175-4199. doi: 10.1007/s00253-015-6582-5.

FAO. 2002. Report of a Joint Food and Agriculture Organization/World Health Organization (FAO/WHO): Working Group on Drafting Guidelines for the Evaluation of Probiotics in Food. Retrieved 21 Jan, 2017.

Folland, J. P., \& Williams, A. G. 2007. The adaptations to strength training : morphological and neurological contributions to increased strength. Sports Med. 37(2), 145-168.

Georges, J., Lowery, R. P., Yaman, G., Kerio, C., Ormes, J., McCleary, S. A., et al. 2014. The effects of probiotic supplementation on lean body mass, strength, and power, and health indicators in resistance trained males: a pilot study. J. Int. Soc. Sports Nutr. 11(1), P38. doi: 10.1186/15502783-11-s1-p38. 
Gleeson, M., Bishop, N. C., Oliveira, M., \& Tauler, P. 2011. Daily probiotic's (Lactobacillus casei Shirota) reduction of infection incidence in athletes. Int. J. Sport Nutr. Exerc. Metab. 21(1), $55-64$.

Goldenberg, J. Z., Lytvyn, L., Steurich, J., Parkin, P., Mahant, S., \& Johnston, B. C. 2015. Probiotics for the prevention of pediatric antibiotic-associated diarrhea. Cochrane Database Syst. Rev. (12), Cd004827. doi: 10.1002/14651858.CD004827.pub4.

Guandalini, S. 2011. Probiotics for prevention and treatment of diarrhea. J. Clin. Gastroenterol. 45 Suppl, S149-153. doi: 10.1097/MCG.0b013e3182257e98.

Haywood, B. A., Black, K. E., Baker, D., McGarvey, J., Healey, P., \& Brown, R. C. 2014. Probiotic supplementation reduces the duration and incidence of infections but not severity in elite rugby union players. J. Sci. Med. Sport. 17(4), 356-360. doi: 10.1016/j.jsams.2013.08.004.

Izquierdo, M., Ibanez, J., Calbet, J. A., Navarro-Amezqueta, I., Gonzalez-Izal, M., Idoate, F., et al. 2009. Cytokine and hormone responses to resistance training. Eur. J. Appl. Physiol. 107(4), 397-409. doi: 10.1007/s00421-009-1139-x.

Jäger, R., Purpura, M., Stone, J., Turner, S., Anzalone, A., Eimerbrink, M., et al. 2016. Probiotic Streptococcus thermophilus FP4 and Bifidobacterium breve BR03 Supplementation Attenuates Performance and Range-of-Motion Decrements Following Muscle Damaging Exercise. Nutrients, 8(10), 642.

Jäger, R., Shields, K., Sharp, M., Partl, J., Wilson, J. M., Lowery, R. P., et al. 2015. Effects of probiotic supplementation on markers of skeletal muscle damage, perceived recovery and athletic performance after an intense single leg training bout. J. Int. Soc. Sports Nutr. 12(Suppl 1), P36-P36. doi: 10.1186/1550-2783-12-S1-P36.

Jeon, S. G., Kayama, H., Ueda, Y., Takahashi, T., Asahara, T., Tsuji, H., et al. 2012. Probiotic Bifidobacterium breve Induces IL-10-Producing Tr1 Cells in the Colon. PloS Pathogens, 8(5), e1002714. doi: 10.1371/journal.ppat.1002714. 
Kimmel, M., Keller, D., Farmer, S., \& Warrino, D. E. 2010. A controlled clinical trial to evaluate the effect of GanedenBC(30) on immunological markers. Methods Find Exp. Clin. Pharmacol. 32(2), 129-132. doi: 10.1358/mf.2010.32.2.1423881.

Lamprecht, M., \& Frauwallner, A. 2012. Exercise, intestinal barrier dysfunction and probiotic supplementation. Med. Sport Sci. 59, 47-56. doi: 10.1159/000342169.

Lau, \& Ooi, K. F. 2014. Changes in Blood Bone Turnover Markers following combined circuit Training Programme and Chocolate Malt Drink Supplementation in Young Male. J. Health Allied Sci. 1(1), 9.

Moritani, T., \& deVries, H. A. 1979. Neural factors versus hypertrophy in the time course of muscle strength gain. Am. J. Phys. Med. 58(3), 115-130.

Ooi, F. K., Mohamed H.A, Chen, C. K., \& Asari, M. A. 2015. Combined effects of Eurycoma longifolia Jack supplementation and a circuit training programme on bone metabolism markers, muscular strength and power, and immune functions in adult men. Int. J. Engineering Research Sports Sci. 2(3), 1-10.

Peake, J. M., Neubauer, O., Della Gatta, P. A., \& Nosaka, K. 2017. Muscle damage and inflammation during recovery from exercise. J. Appl. Physiol. 122(3), 559-570. doi: 10.1152/japplphysiol.00971.2016.

Pedersen, B. K., Steensberg, A., \& Schjerling, P. 2001. Muscle-derived interleukin-6: possible biological effects. J. Physiol. 536(Pt 2), 329-337. doi: 10.1111/j.1469-7793.2001.0329c.xd.

Roth, S. M., Martel, G. F., Ivey, F. M., Lemmer, J. T., Metter, E. J., Hurley, B. F., et al. 2000. Highvolume, heavy-resistance strength training and muscle damage in young and older women. J. Appl. Physiol. 88(3), 1112.

Sale, D. G. 1988. Neural adaptation to resistance training. Med. Sci. Sports Exerc. 20(5 Suppl), S135145. 
Schlee, M., Harder, J., Koten, B., Stange, E. F., Wehkamp, J., \& Fellermann, K. 2008. Probiotic lactobacilli and VSL\#3 induce enterocyte beta-defensin 2. Clin. Exp. Immunol. 151(3), 528535. doi: 10.1111/j.1365-2249.2007.03587.x.

Sheil, B., MacSharry, J., O'Callaghan, L., O'Riordan, A., Waters, A., Morgan, J., et al. 2006. Role of interleukin (IL-10) in probiotic-mediated immune modulation: an assessment in wild-type and IL-10 knock-out mice. J. Clin. Exp. Immunol. 144(2), 273-280. doi: 10.1111/j.13652249.2006.03051.x.

Sheridan, P. O., Bindels, L. B., Saulnier, D. M., Reid, G., Nova, E., Holmgren, K., et al. 2014. Can prebiotics and probiotics improve therapeutic outcomes for undernourished individuals? Gut Microbes, 5(1), 74-82. doi: 10.4161/gmic.27252.

Shing, C. M., Peake, J. M., Lim, C. L., Briskey, D., Walsh, N. P., Fortes, M. B., et al. 2014. Effects of probiotics supplementation on gastrointestinal permeability, inflammation and exercise performance in the heat. Eur. J. Appl. Physiol. 114(1), 93-103. doi: 10.1007/s00421-013$2748-\mathrm{y}$

Thomas, C. M., \& Versalovic, J. 2010. Probiotics-host communication: Modulation of signaling pathways in the intestine. Gut Microbes, 1(3), 148-163.

Vinolo, M. A. R., Rodrigues, H. G., Nachbar, R. T., \& Curi, R. 2011. Regulation of Inflammation by Short Chain Fatty Acids. Nutrients, 3(10), 858-876. doi: 10.3390/nu3100858.

West, Pyne, D. B., Cripps, A. W., Hopkins, W. G., Eskesen, D. C., Jairath, A., et al. 2011. Lactobacillus fermentum (PCC(R)) supplementation and gastrointestinal and respiratory-tract illness symptoms: a randomised control trial in athletes. Nutr. J. 10, 30. doi: 10.1186/14752891-10-30. 
Table 1. Physiological characteristics of the participants

\begin{tabular}{|c|c|c|c|c|c|c|c|c|c|}
\hline Variables & $\begin{array}{l}\text { Age } \\
\text { (years) }\end{array}$ & $\begin{array}{c}\text { Body } \\
\text { height }(\mathrm{cm})\end{array}$ & & $\begin{array}{c}\text { Body } \\
\text { weight }(\mathrm{kg})\end{array}$ & $\begin{array}{l}\text { Body mass index } \\
\text { (BMI) }\left(\mathrm{kg} / \mathrm{m}^{2}\right)\end{array}$ & $\begin{array}{c}\text { Body Fat } \\
\text { Percentage (\%) }\end{array}$ & $\begin{array}{l}\text { Resting Heart } \\
\text { Rate (bpm) }\end{array}$ & $\begin{array}{c}\text { Systolic Blood } \\
\text { Pressure (mmHg) }\end{array}$ & $\begin{array}{l}\text { Diastolic Blood } \\
\text { Pressure (mmHg) }\end{array}$ \\
\hline \multirow[t]{2}{*}{$C(n=10)$} & $22 \pm 2$ & $170.4 \pm 7.2$ & Pre-test & $61.4 \pm 10.4$ & $21.1 \pm 2.8$ & $18.6 \pm 7.3$ & $72.9 \pm 2.6$ & $117.6 \pm 3.7$ & $70.4 \pm 1.1$ \\
\hline & & & Post-test & $61.8 \pm 10.5$ & $21.3 \pm 2.9$ & $19.8 \pm 7.2$ & $72.6 \pm 3.4$ & $120.0 \pm 2.7$ & $71.8 \pm 1.5$ \\
\hline$P(n=10)$ & & & Post-test & $62.4 \pm 11.5$ & $21.5 \pm 3.8$ & $20.1 \pm 6.7$ & $68.5 \pm 2.3$ & $121.4 \pm 3.0$ & $71.0 \pm 2.2$ \\
\hline $\begin{array}{c}\mathrm{CT} \\
(\mathrm{n}=12)\end{array}$ & $21 \pm 2$ & $169.3 \pm 7.0$ & Pre-test & $60.6 \pm 9.9$ & $21.1 \pm 2.7$ & $18.3 \pm 6.8$ & $71.7 \pm 2.5$ & $118.0 \pm 3.2$ & $70.7 \pm 1.5$ \\
\hline $\begin{array}{l}\text { CTP } \\
(\mathrm{n}=9)\end{array}$ & & & Post-test & $63.7 \pm 11.4$ & $21.9 \pm 3.9$ & $20.7 \pm 6.8$ & $68.3 \pm 2.6$ & $121.8 \pm 3.3$ & $71.1 \pm 3.5$ \\
\hline
\end{tabular}

$\mathrm{C}$ - sedentary with placebo control group; P - probiotics group; CT - exercise group; CTP - combined probiotics with exercise group. 
Table 2. IL- 6 and IL-10 concentrations before and after the intervention

\begin{tabular}{|c|c|c|c|c|c|c|}
\hline \multirow{2}{*}{ Groups } & \multicolumn{2}{|c|}{ IL-6 concentration (pg/mL) } & \multirow{2}{*}{$\begin{array}{l}\text { Percent } \\
\text { difference } \\
(\%)\end{array}$} & \multicolumn{2}{|c|}{ IL-10 concentration (pg/mL) } & \multirow{2}{*}{$\begin{array}{l}\text { Percent } \\
\text { difference } \\
(\%)\end{array}$} \\
\hline & Pre-test & Post-test & & Pre-test & Post-test & \\
\hline $\mathrm{C}$ & $13.99 \pm 1.06$ & $14.36 \pm 2.07$ & +2.64 & $4.82 \pm 1.99$ & $7.21 \pm 0.83$ & +49.59 \\
\hline $\mathrm{P}$ & $13.12 \pm 1.61$ & $12.66 \pm 1.50$ & -3.51 & $5.99 \pm 1.29$ & $9.99 \pm 4.93^{*}$ & +66.78 \\
\hline $\mathrm{CT}$ & $12.83 \pm 1.57$ & $13.77 \pm 1.01$ & +7.33 & $5.20 \pm 1.71$ & $9.23 \pm 2.96^{*}$ & +77.50 \\
\hline CTP & $12.82 \pm 1.13$ & $12.03 \pm 1.05$ & -6.16 & $4.47 \pm 0.84$ & $7.70 \pm 3.41$ & +72.26 \\
\hline
\end{tabular}

Values are tabulated as means \pm standard deviation $(\mathrm{SD})$.

$*$, Significantly difference from pre-test $(\mathrm{p}<0.05)$.

$\mathrm{C}$ - sedentary with placebo control group; P - probiotics group; CT - exercise group; CTP - combined probiotics with exercise group. 
Figure 1. CONSORT (Consolidated Standards of Reporting Trials) diagram of study recruitment, enrollment, randomization and analysis. ${ }^{*}$, Significantly difference from pre-test $(P<0.05)$

Figure 2. (a) mean dominant knee extension peak torque at $90^{\circ} . \mathrm{s}^{-1}$, (b) mean non-dominant knee extension peak torque at $90^{\circ} \cdot \mathrm{s}^{-1}$, (c) mean dominant knee flexion peak torque at $90^{\circ} \cdot \mathrm{s}^{-1}$, (d) mean nondominant knee flexion peak torque at $90^{\circ} . \mathrm{s}^{-1}$, (e) mean dominant extension average power at $300^{\circ} . \mathrm{s}^{-1}$, (f) mean non-dominant knee extension average power at $300^{\circ} \cdot \mathrm{s}^{-1},(\mathrm{~g})$ mean dominant flexion average power at $300^{\circ} \cdot \mathrm{s}^{-1}$ and (h) mean non-dominant knee flexion average power at $300^{\circ} \cdot \mathrm{s}^{-1}$. 


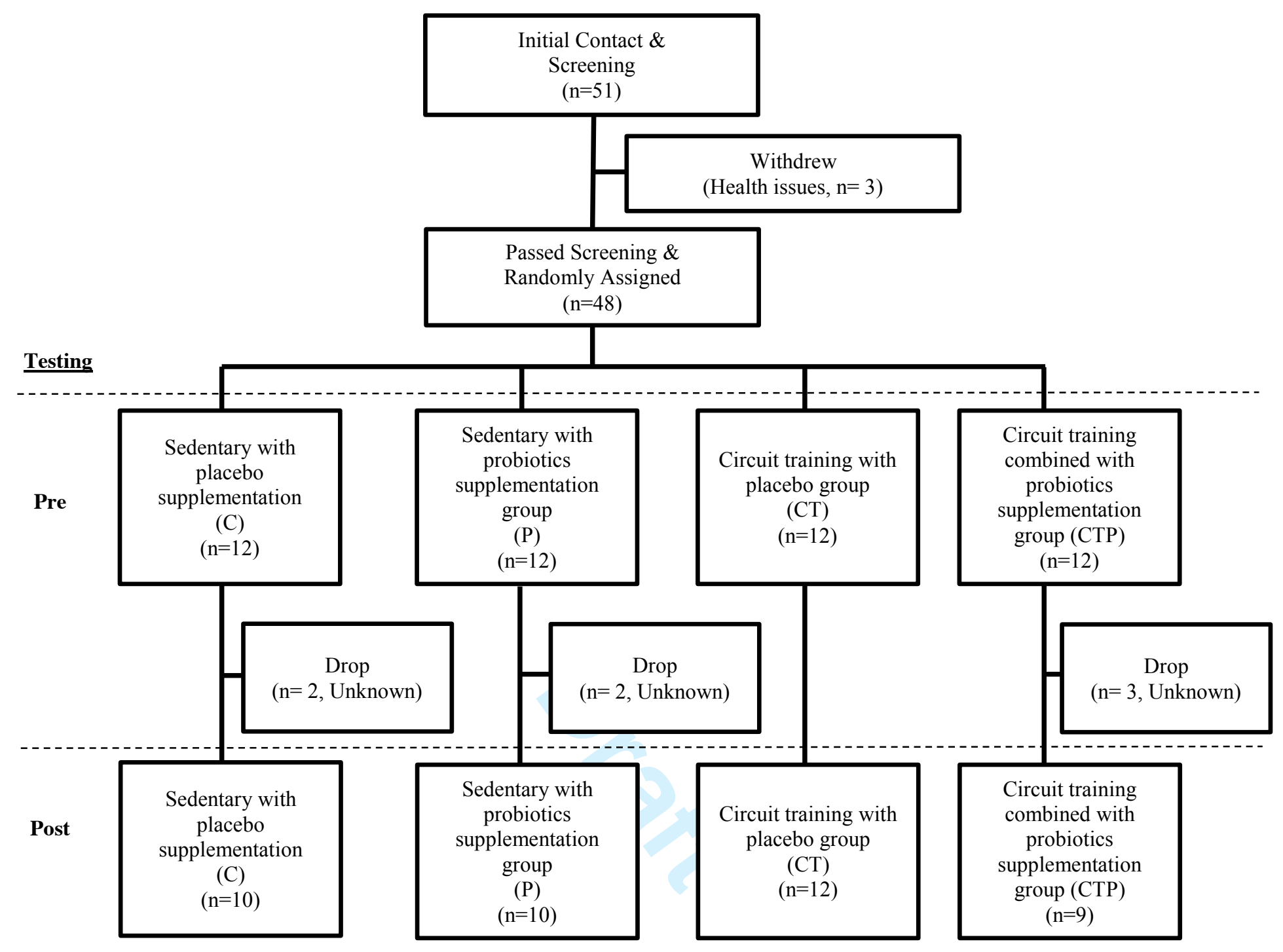


(a)

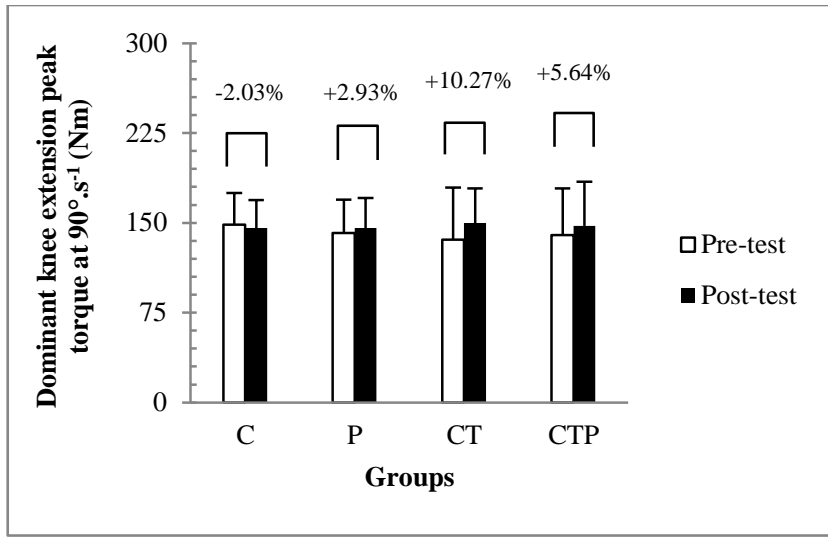

(c)

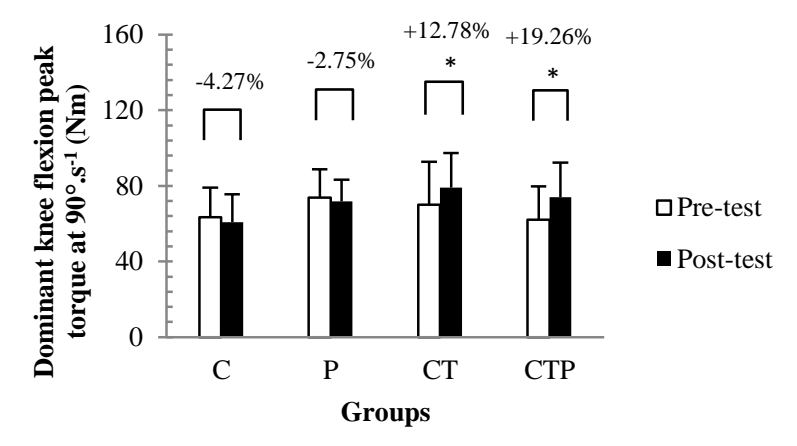

(e)

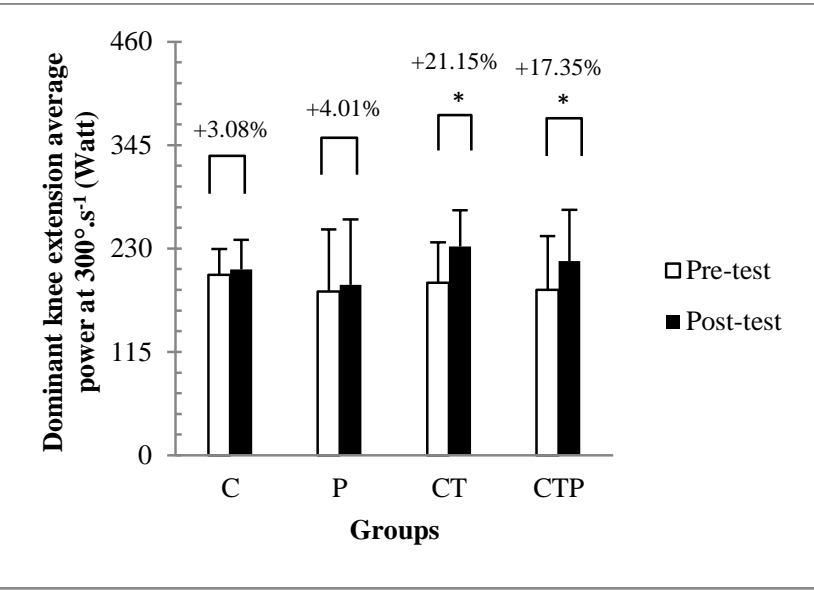

$(\mathrm{g})$

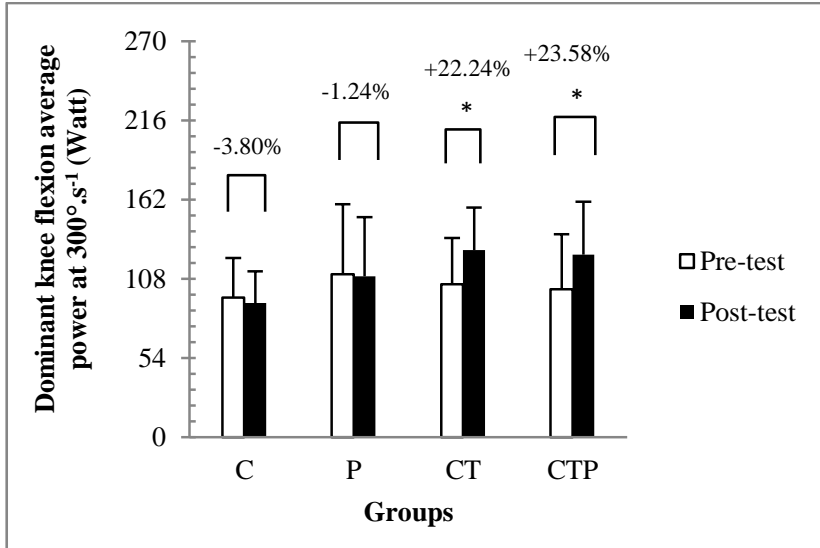

(b)

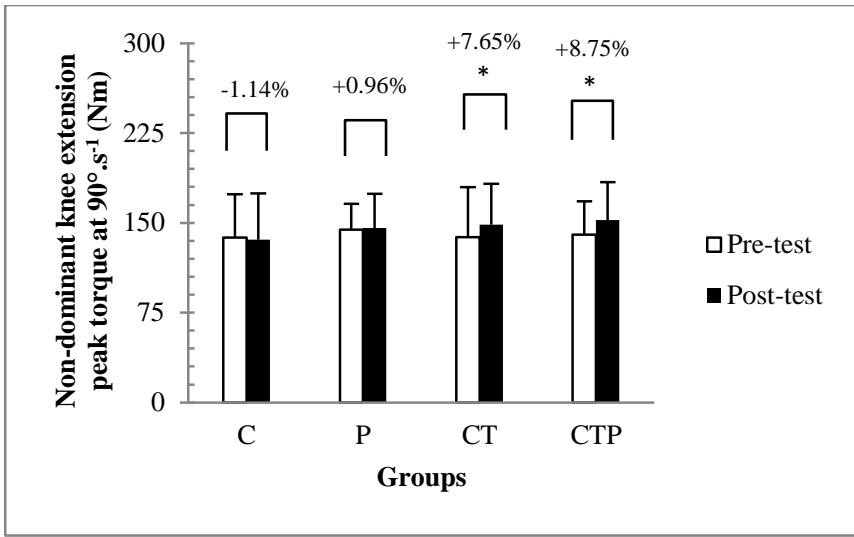

(d)

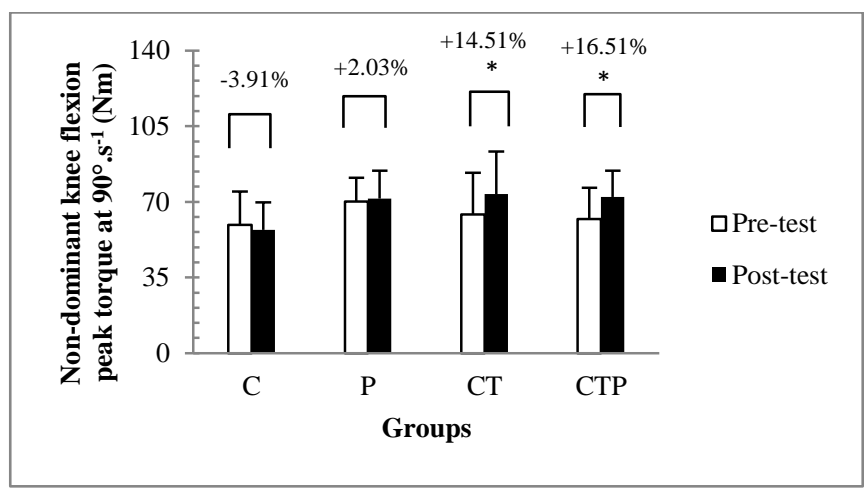

(f)

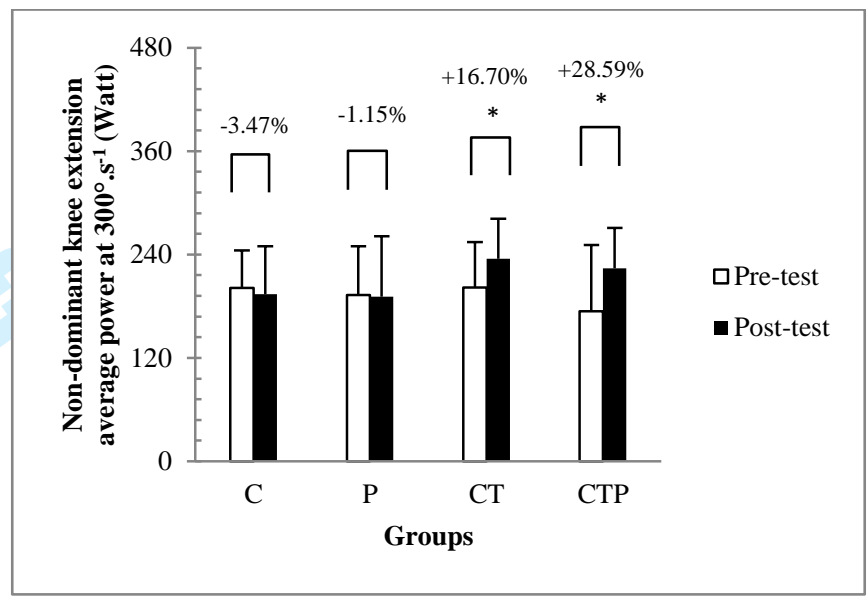

(h)

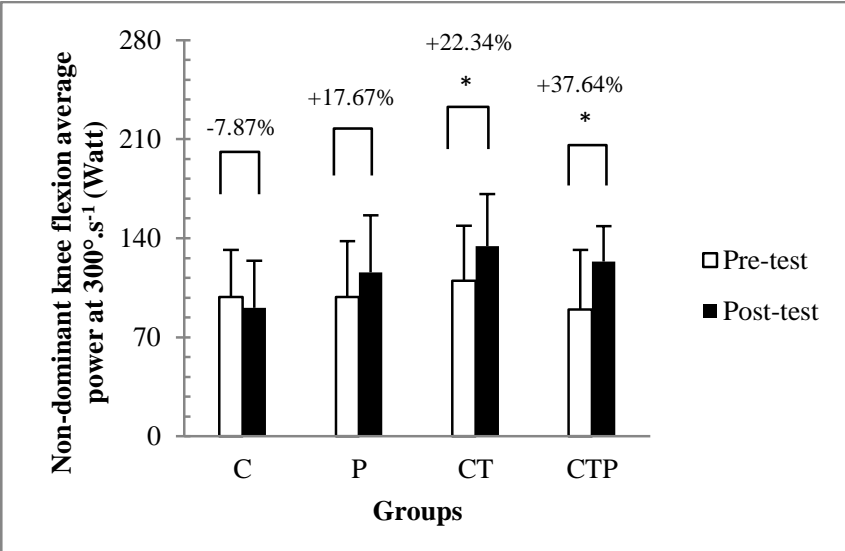

